CLINICAL STUDY

\title{
Immunoanalysis indicates that the sodium iodide symporter is not overexpressed in intracellular compartments in thyroid and breast cancers
}

\author{
Isabelle Peyrottes, Valerie Navarro ${ }^{1}$, Alejandro Ondo-Mendez ${ }^{1,2}$, Didier Marcellin ${ }^{3}$, Laurent Bellanger ${ }^{3}$, \\ Robert Marsault $^{1}$, Sabine Lindenthal ${ }^{1}$, Francette Ettore, Jacques Darcourt ${ }^{1}$ and Thierry Pourcher ${ }^{1}$ \\ Department of Pathology, Center Antoine Lacassagne, 06100, Nice, France, ${ }^{1}$ TIRO, CEA DSV-iBEB-SBTN, CAL, School of Medicine, University of Nice \\ Sophia Antipolis, 28, Avenue de Valombrose, 06107 Nice, France, ${ }^{2}$ Laboratory of Biophysics, CIF, University of Colombia, Bogota, Colombia and ${ }^{3}$ CEA \\ center of Marcoule, DSV-iBEB-SBTN, Bagnols-sur-Cèze, France \\ (Correspondence should be addressed to T Pourcher; Email: pourcher@unice.fr)
}

\begin{abstract}
Objective: The active transport of iodide into thyroid cells is mediated by the $\mathrm{Na}^{+} / \mathrm{I}^{-}$symporter (NIS) located in the basolateral membrane. Strong intracellular staining with anti-NIS antibodies has been reported in thyroid and breast cancers. Our initial objective was to screen tumour samples for intracellular NIS staining and then to study the mechanisms underlying the altered subcellular localization of the transporters.

Methods: Immunostaining using three different anti-NIS antibodies was performed on paraffinembedded tissue sections from 93 thyroid or breast cancers. Western blot experiments were carried out to determine the amount of NIS protein in 20 samples.

Results: Using three different anti-NIS antibodies, we observed intracellular staining in a majority of thyroid tumour samples. Control immunohistochemistry and western blot experiments indicated that this intracellular staining was due to non-specific binding of the antibodies. In breast tumours, very weak intracellular staining was observed in some samples. Western blot experiments suggest that this labelling is also non-specific.

Conclusions: Our results strongly indicate that the NIS protein level is low in thyroid and breast cancers and that the intracellular staining obtained with anti-NIS antibodies corresponds to a non-specific signal. Accordingly, to increase the efficiency of radiotherapy for thyroid cancers and to enable the use of radioiodine in the diagnosis and therapy of breast tumours, improving NIS targeting to the plasma membrane will not be sufficient. Instead, increasing the expression level of NIS should remain the major goal of this field.
\end{abstract}

European Journal of Endocrinology $160215-225$

\section{Introduction}

The sodium-iodide symporter (NIS) is the key protein responsible for the transport and concentration of iodide from the blood into the thyroid gland. The rat NIS sequence was the first to be identified (1) followed by the human (2) and mouse sequences (3). NIS (also called SLC5A5), a member of the sodium/solute symporter family, is an integral membrane protein that resides in the basolateral membrane of thyroid epithelial cells (for review see (4)). Predicted and experimental data indicate that the protein is organized into 13 membranespanning domains (5) and contains three N-linked carbohydrates (5). NIS catalyzes the accumulation of iodide from the blood into the thyrocytes through the basolateral membrane. Once in the cell, the iodide is translocated across the apical membrane into the follicular lumen, where it is immediately organified into thyroglobulin, the thyroid hormone precursor. NIS is also expressed in other organs such as the lactating mammary gland, the salivary gland and the stomach, where it catalyzes iodide accumulation.

For decades, the NIS-mediated iodide accumulation observed in thyrocytes has been an useful tool for the diagnosis (thyroid scintiscan) and treatment (radiotherapy) of various thyroid diseases. Most thyroid cancers are associated with a decreased iodide accumulation capacity appearing as 'cold' nodules. Following the identification of the human NIS cDNA, as reported by several groups (6-14), it is now well established that thyroid cancer cells have lower NIS mRNA levels than normal tissues, explaining the decreased iodide uptake. Several early publications reported a lower level of 
NIS protein expression in thyroid tumours (15-17), confirming the expected correlation between low levels of NIS mRNA, NIS protein and iodide accumulation. Later, two groups reported results from immunohistochemistry experiments suggesting that the protein is overexpressed in a majority of thyroid cancers or in non-functioning benign thyroid nodules, but that the protein, instead of being located at the basolateral membrane, is predominantly intracellular (18-21).

It has been established that NIS expression is also induced in the mammary gland during lactation (3, $22,23)$. Iodide uptake was also detected in nonlactating mammary glands in particular cases (24). Further, Tazebay and collaborators observed that $80 \%$ of breast tumours exhibited intracellular staining with anti-NIS antibodies (22). In another study, staining with anti-NIS antibodies was detected in a majority of breast tumours and other carcinomas (19). These authors proposed that NIS is expressed in breast tumours, but that defective targeting of the protein to the plasma membrane leads to the non-existent or low transport capacities.

A better understanding of the molecular mechanisms involved in the iodide transport capacity and posttranscriptional regulation and targeting of the NIS protein in thyroid cancer cells would likely be useful for improving ${ }^{131} \mathrm{I}$ radioablation therapy. In addition, increasing NIS expression in breast cancer cells may allow the use of iodide transport for the diagnosis and treatment of these tumours and related metastases. This work was initiated with the goal of obtaining, from our tissue bank, biological material for further studies in which the NIS protein is not correctly located at the plasma membrane. For this purpose, we analyzed the NIS expression in surgical tissue specimens from patients with various thyroid pathologies or breast cancers.

\section{Materials and methods}

\section{Patients}

All the samples were selected after histological examination and classified according to the World Health
Organization recommendations (25). The immunohistochemistry (using three anti-NIS antibodies) included 72 patients who underwent surgery for different thyroid pathologies (Table 1): 9 Graves's disease; 16 adenomas; 27 papillary carcinomas; 15 follicular carcinomas; and 5 medullary carcinomas. Several samples of normal thyroids (from patients who underwent surgery for other pathologies) were also used for control experiments. Additional samples were used for the western blot analysis: 8 Graves's disease (as positive controls) and 11 papillary carcinomas. The same samples were also studied using immunohistochemistry using one anti-NIS antibody. The results (data not shown) were similar to those of Table 1. Patients were living in the region of the city of Nice, an iodine-sufficient area. Thirty samples of ductal breast cancers (ten of each grade (I, II and III)) were used for the immunohistochemical analysis and nine out of these samples for immunoblot analysis. Surgical tissue specimens were dissected and several tissue samples prepared. For histological studies of the tumours, the isolated samples included both tumour tissue and surrounding normal tissue. The tissues were fixed in 10\% formalin and embedded in paraffin. For immunoblot analysis, tumour samples were carefully dissected and all normal tissue was removed. Samples of surrounding normal tissue were also prepared. Tissue samples were quickly frozen and stored in liquid nitrogen.

\section{Antibodies}

The primary monoclonal anti-NIS antibody $39 \mathrm{~S}(\mathrm{Ab}$ 39S anti-NIS) was obtained by immunizing mice with purified human NIS protein and fusion of their splenocytes with a mouse myeloma cell line (ATCC\#CRL-1580) according to the standard protocols (26). The epitope recognized by the $39 \mathrm{~S}$ antibody is located between amino acids 580-600 (data not shown). The mouse monoclonal anti-NIS antibody Ab-1 (NeoMarkers, Fremont, CA, USA), clone FP5A, was purchased from Interchim (Montlucon, France). The FP5A antibody recognizes a peptide corresponding to amino acids 625-643 (17). These two antibodies are

Table 1 Anti-NIS antibody staining in thyroid cancers.

\begin{tabular}{|c|c|c|c|c|c|}
\hline $\begin{array}{l}\text { Diagnosis of thyroid } \\
\text { scan }\end{array}$ & $\begin{array}{l}\text { Number of } \\
\text { patients }\end{array}$ & $\begin{array}{l}\text { Membrane } \\
\text { staining }\end{array}$ & $\begin{array}{l}\text { Cytoplasmic } \\
\text { staining }\end{array}$ & $\begin{array}{c}\text { Membrane and } \\
\text { cytoplasmic staining }\end{array}$ & No staining \\
\hline Graves' disease & 9 & 9 & 0 & 0 & 0 \\
\hline \multicolumn{6}{|l|}{ Oncocytic adenomas } \\
\hline Cold & 6 & 0 & 5 & 0 & 1 \\
\hline Hot & 1 & 0 & 0 & 1 & 0 \\
\hline \multicolumn{6}{|c|}{ Non-oncocytic adenomas } \\
\hline Cold & 5 & 0 & 0 & 0 & 5 \\
\hline Hot & 4 & 4 & 0 & 0 & 0 \\
\hline Papillary carcinomas & 27 & 0 & 15 & 0 & 12 \\
\hline Follicular carcinomas & 15 & 0 & 9 & 0 & 6 \\
\hline Medullary carcinomas & 5 & 0 & 0 & 0 & 5 \\
\hline
\end{tabular}


specific for NIS, as shown in western blot experiments performed on membrane proteins from NIS-expressing cells. The 39S and FP5A antibodies reveal a major band with a molecular weight of $\sim 90 \mathrm{kDa}$, corresponding to the fully glycosylated protein, as well as additional minor bands (see Dayem and collaborators for the 39S antibody (27) and Castro and collaborators for the FP5A antibody (17)). The mouse monoclonal anti-NIS antibody VJ1 (28), obtained by genetic immunization, was a generous gift from Dr Costagliola (IRIBHN, Brussels, Belgium). The epitope recognized by the VJ1 antibody is not well defined, but is presumably located at the cell surface and probably, as has been proposed for VJ2, contains amino acids located within the last extracellular loop (28). This antibody does not recognize denatured NIS protein following SDS-PAGE. For control experiments, a monoclonal anti-CD45 antibody (clone 2B11 from Dako France, Trappes, France) and an oestrogen receptor (ER) antibody (diluted preparation of clone SP1 from Ventana, Illkirch, France) were used.

\section{Immunohistochemistry}

The tissues were fixed in 10\% formalin and embedded in paraffin. Sections $(2.5 \mu \mathrm{m}$ thick) were deparaffinized, rehydrated and immunostained using an automated immunostainer (Benchmark XT, Ventana Medical Systems) with standardized duration and temperature for all steps. Endogenous peroxide and biotin activities were blocked using the Ventana iVIEWTM inhibitor. The sections were blocked according to the standard protocol from Ventana. The blocking agents are goat IgG and casein. After pre-treatment, slides were incubated for $32 \mathrm{~min}$ at $37^{\circ} \mathrm{C}$ with one of the three anti-human NIS antibodies at concentrations of $3 \mu \mathrm{g} / \mathrm{ml}$ for $39 \mathrm{~S} \mathrm{Ab}$ and $0.2 \mu \mathrm{g} / \mathrm{ml}$ for hNISAb- 1 (FP5A), and at a 1:150 dilution for VJ1 Ab. For control experiments, a monoclonal anti-CD45 antibody (Clone 2B11 from Dako France, Trappes, France) was used at a 1:300 dilution. For ER immunostaining, a diluted preparation of clone SP1 from Ventana was employed. Immunostaining of all the samples was performed with a Basic DAB Detection kit (Ventana Medical Systems), following the standard protocol. After washing, all slides were counterstained with haematoxylin. In each case, serial slides were stained with haematoxylin-eosin for histological evaluation. Image acquisition was performed using an Olympus DX52 microscope (Olympus France, Rungis, France) equipped with an Olympus DP70 Camera.

\section{Preparation of membrane vesicles}

All the preparations were carried out at $4{ }^{\circ} \mathrm{C}$. Samples of human thyroids (100-200 mg) or breasts (100-300 mg) were thawed in $250 \mathrm{mM}$ sucrose,
$10 \mathrm{mM}$ HEPES-KOH (pH 7.5), $10 \mathrm{mM} \mathrm{NaCl,} 1 \mathrm{mM}$ $\mathrm{CaCl}_{2}, 1 \mathrm{mM} \mathrm{MgCl}$, $1 \mathrm{mM}$ EDTA (1-1.5 ml per $50 \mathrm{mg}$ tissue) and mammalian protease inhibitors (Complete, Roche Diagnostics), and disrupted with a motor-driven Teflon pestle homogenizer (1000 rpm/min). The homogenate was centrifuged at $1000 \mathrm{~g}$ for $10 \mathrm{~min}$ at $4{ }^{\circ} \mathrm{C}$ to eliminate cellular debris. The supernatant was removed and centrifuged at $10000 \mathrm{~g}$ for $10 \mathrm{~min}$ at $4{ }^{\circ} \mathrm{C}$ and the supernatant of this centrifugation was centrifuged at $100000 \mathrm{~g}$ for $1 \mathrm{~h}$ at $4{ }^{\circ} \mathrm{C}$. The pellet (MV) was suspended in $100 \mu \mathrm{l}$ cold $100 \mathrm{mM}$ mannitol, $10 \mathrm{mM}$ HEPES-KOH (pH 7.5), $10 \mathrm{mM} \mathrm{NaCl}$, supplemented with a mammalian protease inhibitor cocktail (Complete, Roche Diagnostics), and stored at $-80^{\circ} \mathrm{C}$.

\section{Western blot analyses}

Thyroid samples ( $80 \mu \mathrm{g}$ membrane protein) were mixed with $2 \times$ loading buffer (Sigma-Aldrich) and incubated for $40 \mathrm{~min}$ at $42{ }^{\circ} \mathrm{C}$ prior to electrophoresis. Proteins were separated on SDS/PAGE (4-15\% Ready Gel Precast Gels, Bio-Rad) and transferred to a PVDF membrane (Hybond-ECL, GE healthcare, Saclay, France). Membranes were saturated for $45 \mathrm{~min}$ in blocking buffer (PBS, 2 g/l casein from I-Block, Tropix, Bedford, MA, USA) and then incubated for $2 \mathrm{~h}$ at room temperature with the primary antibody. Subsequently, membranes were washed thrice for $10 \mathrm{~min}$ in PBS buffer and incubated with the secondary antibody (an HRP-linked goat anti-mouse IgG (Pierce-Perbio, Brebières, France; dilution 1:5000) for $45 \mathrm{~min}$ at room temperature. Three final washes in PBS buffer were performed. Horseradish peroxidase was revealed by SuperSignal West Pico (Pierce). PVDF membranes were stripped and reprobed with anti-Na ${ }^{+} / \mathrm{K}^{+}$-ATPase MAB (Clone 464.6 from Novus Biologicals, Littleton, CO, USA) or anti-cadherin pan polyclonal antibody (AnaSpec Inc., San Jose, CA, USA) as plasma membrane protein markers.

\section{Results}

\section{Immunohistochemistry in normal thyroid tissues}

All our study was carried out with three monoclonal anti-NIS antibodies to avoid potential non-specific immunoreactivity. These antibodies recognize three different epitopes on the human NIS protein. As reported in many studies, heterogeneous anti-NIS antibody staining was obtained in follicular epithelial cells of the normal thyroid. The FP5A antibody staining is shown in Fig. 1A; the same pattern was obtained using the $39 \mathrm{~S}$ or VJ1 antibodies (data not shown). Only a few cells showed positive staining. In these positive cells, the NIS protein was confined to the basolateral membrane. 

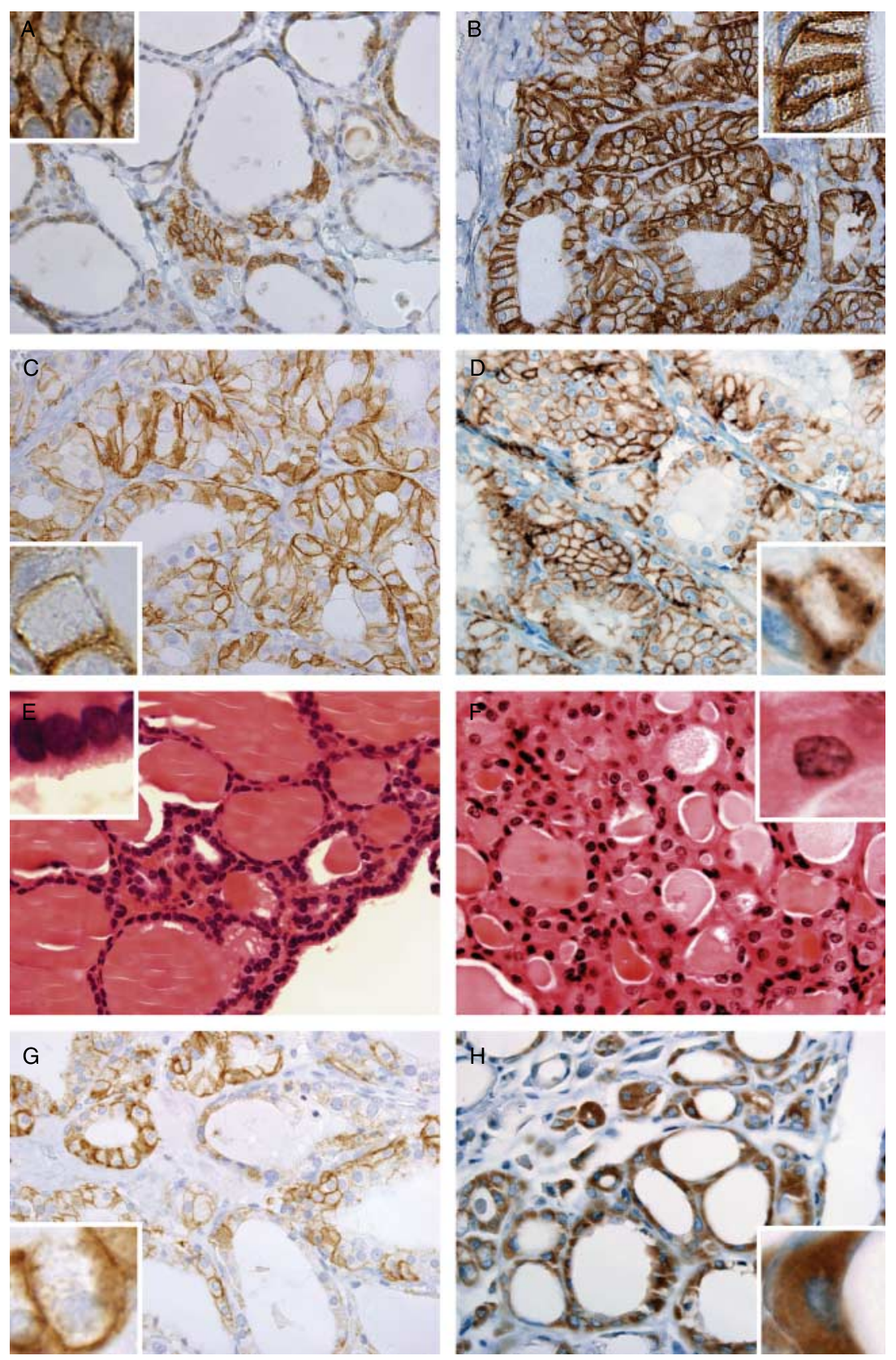

Figure 1 Immunohistochemical analysis of NIS expression and localization in thyroid tissues. (A) Normal thyroid incubated with FP5A antibody; (B-D) thyroid corresponding to Graves' disease incubated with 395 antibody $(3 \mu \mathrm{g} / \mathrm{ml})(B)$, FP5A antibody $(0.2 \mu \mathrm{g} / \mathrm{ml})(\mathrm{C})$ or VJ1 antibody (at a 1:150 dilution) (D). (E and G) Thyroid adenoma stained with haematoxylin-eosin (E) or incubated with FP5A antibody (G). (F) and (H) Oncocytic adenoma stained with haematoxylin-eosin $(F)$ or incubated with FP5A antibody $(\mathrm{H})$. All of the images were taken at a $600 \times$ magnification. Part of the image was enlarged (2.5-fold) and inserted at the corner of each picture. Three criteria were used to classify the anti-NIS antibody staining: intensity of the labelling (ranked from 0 to 3); percentage of positive cells; and subcellular localization of the staining.
No intracellular anti-NIS antibody staining was observed. Most of the cells did not show any labelling. These unlabeled cells were flat and presumably correspond to non-stimulated cells. In all the experiments on thyroid adenomas or carcinomas described above, the normal surrounding tissue was also examined and was used as an internal control for the immunolabelling of each section. This analysis was not only a control for the staining procedure but also expected to ensure the homogeneity of the patients with regard to other factors (i.e. iodide supply (29)) that could modify the NIS expression in the thyroid.

\section{Immunohistochemistry in thyroid tissues corresponding to Graves' disease}

Homogeneous anti-NIS antibody labelling was obtained in follicular epithelial cells from thyroids of patients with Graves' disease. Almost, all the cells showed strong positive staining confined to the basolateral membrane. The same pattern was obtained with the $39 \mathrm{~S}$ (Fig. 1B), FP5A (Fig. 1C) and VJ1 (Fig. 1D) antibodies. However, when we compared serial sections from a single sample (as shown in Fig. 1B-D), the labelling was stronger but more spread out with the $39 \mathrm{~S}$ antibody. For each set of 
experiments described below, a thyroid section corresponding to Graves' disease was used as a positive control.

\section{Immunohistochemistry in thyroid adenomas}

The selection of thyroid adenomas was based on histological examination. Selected samples were classified into two groups: samples that contained oncocytic cells (also call 'Hürthle cells'), and those that did not. The oncocytic nature of the cells was revealed by an abundant and faintly granular cytoplasm and a large nucleus with prominent nucleolus upon haematoxylin-eosin staining (compare Fig. 1E with F). Based on this classification, the immunohistochemistry experiments were carried out. In the first group, which included seven thyroid adenomas with oncocytic cells, strong intracellular staining was observed in five adenomas (illustrated in Fig. 1H). One of them also exhibited staining of both the cytoplasm and the basolateral membrane. This adenoma was previously characterized after thyroid scintiscan using ${ }^{99} \mathrm{mcO}_{4}$ and corresponded to hyperfunctioning adenomas (toxic adenomas). In the second group, which included nine thyroid adenomas without oncocytic cells, the cells were similar to normal cells (Fig. 1E). Four samples exhibited positive anti-NIS antibody staining of the basolateral membrane (Fig. 1G); all were previously characterized after thyroid scintiscan and corresponded to toxic adenomas. No staining was observed in the five other adenomas. These adenomas were characterized by scintiscan imaging and all corresponded to hypofunctioning areas.

\section{Immunohistochemistry in thyroid papillary carcinomas}

Two sets of experiments were carried out with thyroid papillary carcinomas. In the first set of 16 papillary carcinomas, we observed intracellular anti-NIS antibody staining in eight samples (illustrated in Fig. 2A). The other eight papillary carcinomas did not show any antiNIS antibody staining (illustrated in Fig. 2B). Next, we decided to exclude papillary carcinomas that contained cells with oncocytoid features (characterized only by an abundant and faintly granular cytoplasm) in the second set of experiments. Eleven new carcinomas were chosen. In 7 out of the 11, NIS-staining localized to the cytoplasm was observed (illustrated in Fig. 2C). However, the NIS-labelling intensities were lower than those obtained with the first set of specimens (compare Fig. 2A and $\mathrm{C}$ ).

\section{Immunohistochemistry in follicular carcinoma}

In 9 out of the 15 follicular carcinomas, we observed intracellular anti-NIS antibody staining (Fig. 2D and E).
The intracellular staining was granular. No staining of the basolateral membrane was detected.

\section{Immunohistochemistry in medullary carcinomas}

None of the five medullary carcinomas showed anti-NIS antibody staining.

\section{Immunohistochemistry in thyroid tissues corresponding to Hashimoto's disease}

Immunoreactivity with the same anti-NIS antibodies was also analyzed in the thyroids of several patients with Hashimoto's disease. Anti-NIS antibody staining was confined to a few follicles. In these cells, the staining was clearly intracellular but not intense. We noted that these cells corresponded to oncocytic metaplasias surrounding lymphocyte infiltrations (Fig. 2H).

\section{The immunohistochemistry pattern observed with anti-NIS antibodies was also obtained with other antibodies and was also found in hepatocytes}

As the anti-NIS antibody staining was repeatedly linked to the oncocytoid appearance of the cells, we postulated that the anti-NIS antibody labelling could be due to non-specific binding of our anti-NIS antibodies. Therefore, we studied the immunohistochemistry pattern obtained using antibodies directed against other proteins. The first antibody was directed against CD45, a transmembrane protein tyrosine-specific phosphatase (PTPase). The second antibody was directed against the ER. Both proteins are not expressed in thyrocytes. In all the tested samples showing intracellular anti-NIS antibody staining, both antibodies gave rise to similar staining patterns. One example is illustrated in Fig. 2E-G. In this follicular carcinoma, similar intracellular staining was obtained with antiNIS, anti-CD45 and anti-ER antibodies. In addition, we observed intracellular anti-NIS antibody staining in hepatocytes (Fig. 2I) that have oncocytoid features (i.e. abundant mitochondria) and are not expected to express NIS. These results indicated that the intracellular anti-NIS staining observed in thyroid cancers is not related to the specific binding of the antibody or to NIS overexpression.

\section{Western blot analysis of thyroid samples}

Western blots were performed to determine the level of NIS protein in thyroid samples. Only the largest tumours could be used for this analysis. Eleven papillary tumour samples were selected and carefully dissected. A portion of each sample was analyzed by immunohistochemistry using anti-hNIS antibodies. They were included in the above study (Table 1). These samples correspond to 

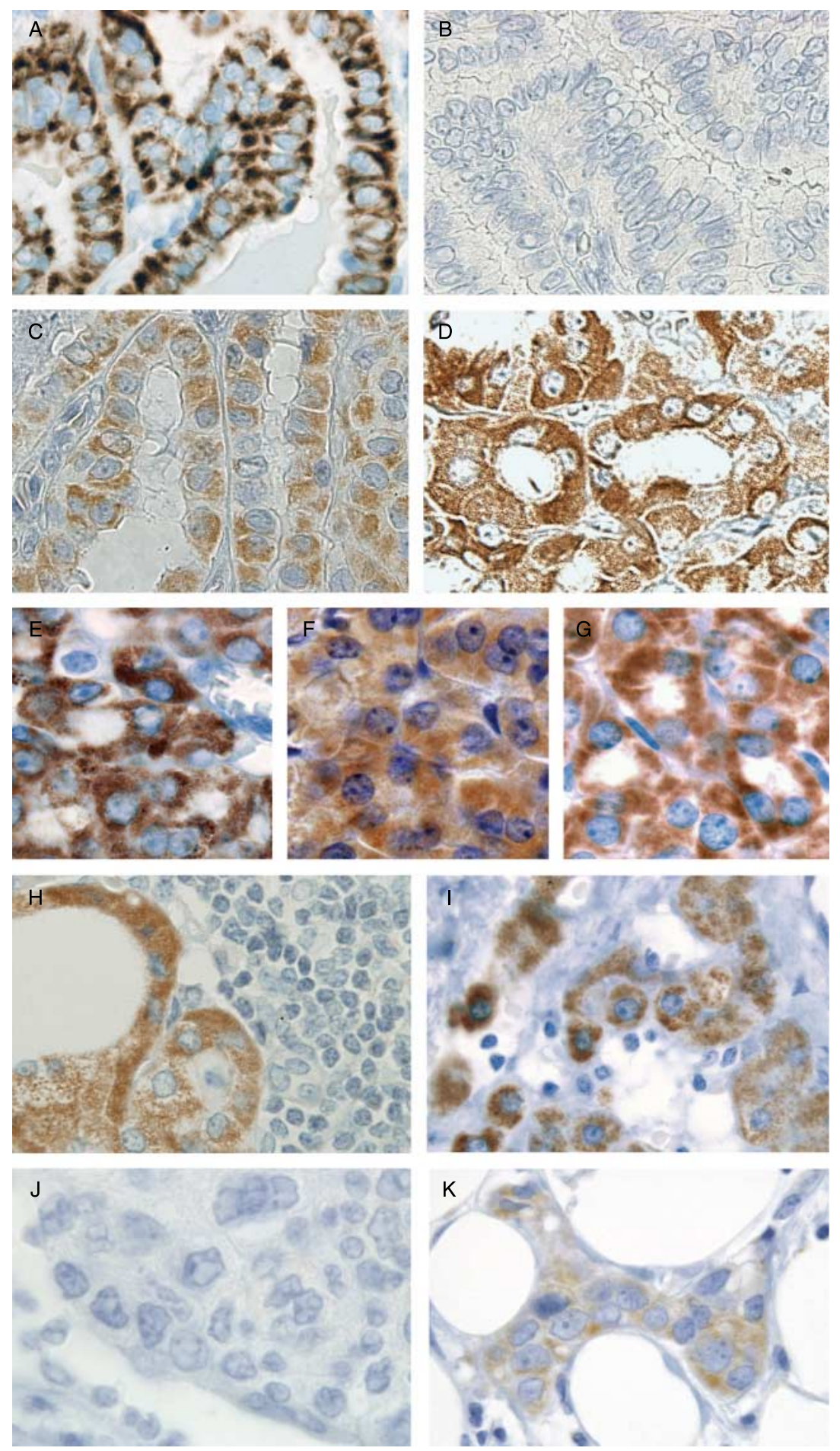

Figure 2 Immunohistochemical analysis of NIS expression and localization in carcinoma thyroid tissues. (A) and (B) Two papillary carcinomas incubated with FP5A antibody; (C) papillary carcinoma incubated with VJ1 antibody; (D) follicular carcinoma incubated with 39S antibody; (E-G), follicular carcinoma incubated with 39S antibody (E), CD45-directed antibody (at 1:300 dilution) (F) or ER-directed antibody $(G)$; (H) oncocytic metaplasias surrounding lymphocyte infiltrations in thyroid tissues corresponding to Hashimoto's disease incubated with VJ1 antibody; (I) oncocytic hepatocyte incubated with VJ1 antibody; $(\mathrm{J})$ and $(\mathrm{K})$ two ductal breast cancers incubated with VJ1 antibody. Images were taken at a $600 \times$ magnification and enlarged 1.75-fold. various intracellular anti-NIS antibody staining behaviours: five did not show staining; in two samples the labelling was low; it was strong in two others and intermediate in the two remaining carcinomas. Surrounding normal tissue was completely removed from the portion of the tumour used for western blots. Membrane fractions were prepared and analyzed. Nine thyroid samples from patients with Graves' disease were used as positive controls. It is well established that the fully glycosylated hNIS protein migrates with a 
molecular weight of $\sim 90 \mathrm{kDa}$. While a corresponding band was observed with thyroid samples corresponding to Graves' disease (illustrated in Fig. 3, lanes 4-5), no corresponding bands were observed with the thyroid tumour samples (illustrated in Fig. 3, lanes 1-3). By contrast, a band migrating with a molecular weight of $\sim 50 \mathrm{kDa}$ was observed in the tumour samples (Fig. 3). The $50 \mathrm{kDa}$ band is believed to correspond to partially glycosylated NIS protein as already demonstrated (30, 31). Further, an additional, strong $15 \mathrm{kDa}$ band was present in thyroid samples corresponding to Graves' disease. This $15 \mathrm{kDa}$ band was also present in most thyroid cancer samples (Fig. 3). We did not observe any relationship between the intensities of the 90, 50 and $15 \mathrm{kDa}$ bands and the intracellular staining. These results corroborated that the intracellular anti-NIS staining in thyroid cancers is not related to specific binding of the antibody or to NIS overexpression.

\section{NIS expression in breast cancers}

The histological grade of breast tumours was assessed by the method of Scarff, Bloom and Richardson (SBR) as modified by Elston and Ellis (32). Ten specimens each of ductal breast cancer tissue of SBR grade I, II or III were studied. Using the same labelling conditions as described above for thyroid samples, immunohistochemical analysis was performed. No significant anti-NIS antibody staining was observed in the 30 breast cancer samples (Fig. 2J). However, some samples did show diffuse and weak anti-NIS antibody staining (Fig. 2K). We, therefore, increased the duration of incubation with the DAB substrate chromogen but these new conditions did not lead to modify our results. We also determined the level of protein expression in nine of these breast tumour samples corresponding to various intracellular anti-NIS antibody staining behaviours. Membrane fractions were prepared and analyzed by western blot. Figure 3 presents results obtained with three representative samples (lanes 6-8). The first is a grade I ductal breast cancer showing no staining with immunohistochemistry. Weak staining in both the plasma membrane and the cytoplasm was observed with the second sample (grade III ductal breast cancer). The third is a grade I ductal breast cancer that showed intracellular staining. For all the breast tumour samples tested, no bands corresponding to the fully glycosylated NIS were observed. As with the thyroid tumours, a $50 \mathrm{kDa}$ band corresponding to partially glycosylated NIS was observed in some breast cancer samples. In addition, a $15 \mathrm{kDa}$ band was also seen in some breast cancer samples; this $15 \mathrm{kDa}$ band was also present in most thyroid cancers. We observed a decrease in a housekeeping plasma protein $\left(\mathrm{Na}^{+} / \mathrm{K}^{+}\right.$-ATPase $)$in some of our breast cancer samples (Fig. 3); the reason for

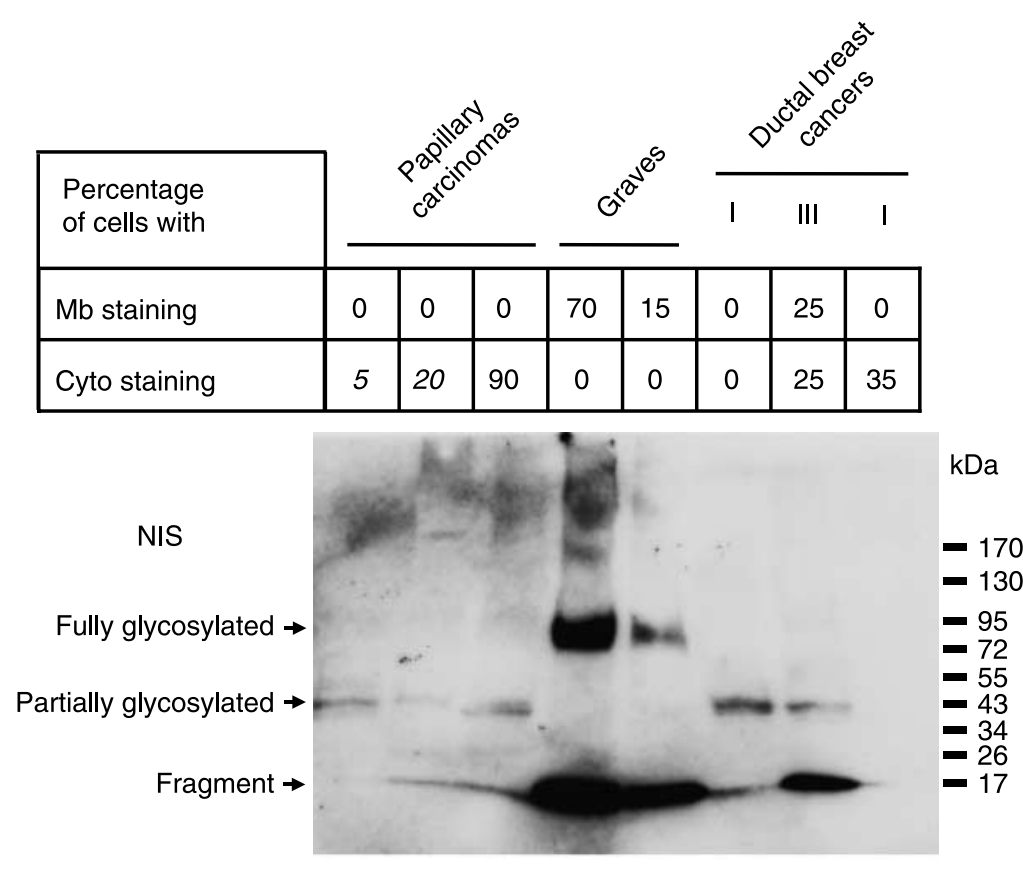

$\mathrm{Na}^{+} / \mathrm{K}^{+}$-ATPase

Pan cadherin

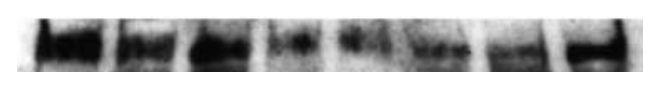

Figure 3 Western blot of NIS in membrane preparations from thyroid tissues. Equal amounts $(40 \mu \mathrm{g})$ of membrane fractions from thyroid or breast tissues were separated on SDS/4-15\% PAGE and were analyzed by immunoblotting. NIS proteins were revealed with the mouse anti-NIS MAB FP5A $(0.2 \mu \mathrm{g} / \mathrm{ml})$. PVDF membrane was stripped and reprobed with anti-Na ${ }^{+} / \mathrm{K}^{+}$-ATPase antibody and anti-cadherin pan antibody. Lane 1: papillary carcinoma with $5 \%$ of the cells showing intracellular anti-NIS antibody staining (parallel immunohistochemical analysis). Lane 2: papillary carcinoma with $20 \%$ of the cells showing intracellular anti-NIS antibody staining (cyto staining). Lane 3: papillary carcinomas with $90 \%$ of the cells showing strong intracellular anti-NIS antibody staining. Lane 4: thyroid corresponding to Graves' disease with $70 \%$ of the cells showing anti-NIS antibody staining confined to the basolateral membrane (mb staining). Lane 5: thyroid corresponding to Graves disease with $15 \%$ of the cells showing anti-NIS antibody staining. Lane 6: ductal breast cancer grade I with no anti-NIS antibody staining. Lane 7: ductal breast cancer grade III with $25 \%$ of the cells showing weak antiNIS antibody staining. Lane 8: ductal breast cancer grade I with $35 \%$ of the cells showing weak intracellular anti-NIS antibody staining. The immunoblots shown are representative of three independent experiments. Molecular weight markers (in $\mathrm{kDa}$ ) are indicated. 
this decrease is unknown. The results obtained with the anti-cadherin pan antibody showed more homogenous results but differences are still observed between the three kinds of samples (papillary carcinomas, Graves and ductal breast cancers). Altogether our results indicated that the level of NIS expression in breast cancers is very low and that the fully glycosylated protein is not present.

\section{Discussion}

The present study was initiated to identify thyroid and breast tissue specimens that contained cells expressing intracellular NIS. Our initial aim was to study the molecular mechanisms that lead to intracellular NIS expression. Our results indicate that the intracellular labelling obtained with the anti-NIS antibodies in thyroid cancers corresponds to a non-specific signal. In addition, we did not observe significant intracellular NIS protein expression in breast cancer samples.

Previous studies have reported that a majority of thyroid cancer samples display intracellular anti-NIS antibody labelling $(18,19)$. These studies used a polyclonal antibody raised against two peptides from the C-terminus of hNIS. The authors proposed that the intracellular expression, or even overexpression, of NIS occurs in most thyroid cancer cells. Another group reported the intracellular overexpression of NIS in more than half of non-functioning benign thyroid nodules using monoclonal anti-NIS antibody VJ2 (20). We also observed intracellular labelling in a majority of thyroid cancer samples using three different monoclonal antibodies. Together, these observations clearly indicate that intracellular labelling is observed in most thyroid tumours using various anti-NIS antibodies.

Oncocytoid cells are characterized by the presence of abundant granular cytoplasm resulting from the aberrant accumulation of mitochondria. Oncocytic cells also show a large nucleus with prominent nucleoli (illustrated in Fig. 1F). As the intracellular anti-NIS antibody staining is also granular, we asked whether this intracellular staining could be related to the oncocytoid character of the cells. Indeed, five out of the six adenomas that contained cells with an oncocytic appearance showed intracellular labelling. By contrast, the five cold adenomas without oncocytic cells did not show intracellular labelling. Toxic adenomas were clearly recognized by strong membrane staining but one sample with oncocytoid cells also showed intracellular labelling. In papillary carcinomas, we first observed, in a first set of experiments, strong intracellular staining in 8 out of the 16 samples. But it was difficult to determine accurately that samples contained more oncocytoid cells. To overcome this difficulty, we decided to exclude papillary carcinomas that contained cells with an oncocytoid appearance in a new set of specimens. We found intracellular anti-NIS antibody staining in 7 out of a total of the 11 samples. However, the intensities were much lower in cells from papillary carcinoma specimens that did not show an oncocytoid appearance. We cannot exclude that some cells of these samples have some oncocytoid behaviours. In addition, intracellular anti-NIS antibody staining was observed in oncocytic metaplasia surrounding lymphocyte infiltrations in thyroid tissues corresponding to Hashimoto's disease. Finally, experiments were carried out on hepatocytes that have oncocytoid features (i.e. abundant mitochondria) and are not expected to express NIS. These cells showed intracellular anti-NIS antibody labelling. Altogether, our observations suggested that the labelling localized to the cytoplasm could be related to the oncocytoid nature of the tumour cells.

To investigate whether the intracellular anti-NIS antibody staining correlated with NIS protein expression, control experiments were carried out with the same specimens using anti-ER and anti-CD45 antibodies. CD45 is a transmembrane tyrosine phosphatase that is abundant in most differentiated haematopoietic cells, but is not expressed in normal or tumour thyroid cells. No specific staining was expected using anti-CD45 antibodies. ER was also expected to be absent from thyroid cells, but a recent publication suggests that ER is expressed in thyroid cancer lines and could contribute to the development of thyroid carcinomas (33). A specific immunostaining of ER is expected to show a different pattern (as nuclear localization). However, the thyroid cancer samples showed similar intracellular staining using anti-NIS, anti-ER or antiCD45 antibodies. Small differences in the labelling intensity could be due to variations in the concentration of the primary antibody used. These experiments indicated that the observed intracellular anti-NIS antibody staining is not related to the specific binding of the antibodies and NIS overexpression. Consequently, a low level of NIS protein expression was expected in thyroid cancer samples regardless of whether or not they showed intracellular staining. Indeed, a low level of (partially glycosylated) NIS protein was found in all thyroid tumour samples when analyzed by western blot. No difference in the protein pattern related to the presence of intracellular anti-NIS antibody staining was observed in corresponding immunohistochemistry experiments. Furthermore, our results suggest that fully glycosylated NIS protein is not present in thyroid tumours. By contrast, in the same experiment, a band corresponding to the fully glycosylated NIS protein was clearly identifiable in thyroid tissues (corresponding to Graves' disease including samples with a number of stained cells close to normal tissues) that showed plasma membrane expression of NIS. Partially glycosylated NIS (50 kDa band) was detected in most of the carcinomas. Similar observations were reported by Trouttet-Masson and collaborators (14). They concluded that the impairment of NIS in thyroid tumours might result from alterations occurring at the transcriptional and post-transcriptional levels. They studied two tumours 
showing a weak intracellular labelling and concluded that this staining correlated to immature NIS. Other reports have suggested that the NIS protein is highly regulated by post-transcriptional events that control, in particular, its subcellular localization (34-36). Partially glycosylated forms of NIS correspond most probably to immature proteins that are not properly processed to the plasma membrane. It should be mentioned that we used a protocol for the preparation of membrane vesicles only excluding the nuclear envelope but comprising all other subcellular membrane fractions. However, as illustrated in Fig. 3 (compare lanes 1, 2 and 3), our western blot experiments did not allow us to correlate the amount of partially glycosylated protein with the intracellular staining (intensity and number of labelled cells) observed in immunohistochemistry experiments. A smaller $15 \mathrm{kDa}$ band (corresponding to a small fragment of NIS, as determined by sequencing and mass spectroscopy, unpublished data) was also detected in most of the papillary tumours. This $15 \mathrm{kDa}$ band was also more clearly observed in thyroid samples representative of Graves' disease. Importantly, this $15 \mathrm{kDa}$ band was recognized by only two of the three different anti-NIS antibodies used in this study (unpublished data). As the three antibodies gave rise to similar intracellular staining in thyroid tumour cells, the intracellular labelling could not result from the staining of this NIS fragment. All these data further support the conclusion that the intracellular anti-NIS antibody staining observed in immunohistochemistry experiments is not related to the presence of NIS protein.

Using the same experimental conditions, we did not observe significant staining in breast cancer samples at different SBR grades (I-III). Strong intracellular antiNIS antibody staining was never observed. These results differ from those published by other groups $(19,22)$. For example, Tazebay and collaborators proposed, for the first time, that the NIS protein is expressed in breast tumours (22). Intracellular anti-NIS antibody staining was reported in $80 \%$ of breast cancer samples. In addition, Wapnir and collaborators (from the same group), using tissue microarrays, found anti-NIS antibody staining in a majority of fibroadenoma and breast tissue samples (19). These authors explained that the observed staining of the cytoplasm made it difficult to discern plasma membrane immunoreactivity. They also reported, using the same conditions and antibodies, intracellular anti-NIS antibody staining in thyroid carcinomas. Using a robot for the labelling procedure, our results were very reproducible within a given set of experiments or between any two sets. For each thyroid cancer sample, the normal tissue surrounding the tumour cells was always studied, and the intensity of the positive staining of normal cells was used as an internal control. For each set of breast cancer samples, at least one thyroid sample was included as a positive control. Nevertheless, our immunohistochemistry analysis showed that, in a majority of breast cancers,
NIS expression was low. We observed strong intracellular staining in a majority of thyroid cancer samples, but only few, very weakly labelled cells in breast cancer tissues. The results presented in the recent publication of Beyer and collaborators (37) could partially explain this discrepancy. The authors analyzed 192 invasive ductal breast carcinomas with immunohistochemistry. They used three different anti-NIS antibodies (\#442, \#836 and VJ1). A similar strong membrane staining confined to the basolateral membrane was observed in thyroid samples corresponding to Graves' disease using any of these three antibodies. Using \#442 affinity purified polyclonal anti-NIS antibodies, intracellular labelling was found in the majority of breast tumours. But, however, using \#836 non-purified polyclonal antiNIS antibodies, intracellular labelling was barely detected in breast tumours. Furthermore, using the monoclonal VJ1 antibody, no intracellular staining was found in breast cancers. The authors proposed that the VJ1 epitope is either not accessible due to posttranscriptional modifications or has a different tertiary structure in breast cancers. We used VJ1 in this study and no significant intracellular labelling was observed in breast cancers. We here described the results obtained on 30 breast cancers but according to the data of Beyer and collaborators we should expect the same result with a larger number of samples. In addition, using the $39 \mathrm{~S}$ and FP5A antibodies, we did not find intracellular staining. Altogether, published results and our observations suggest that the intracellular staining is obtained only with some (preferentially polyclonal) antibodies and therefore could be related to non-specific binding.

In our western blot experiments (Fig. 3), the fully glycosylated protein was undetectable in breast cancer cells. Conversely, partially glycosylated NIS proteins (50 kDa band) and an NIS fragment (15 kDa band) were observed. Although partially glycosylated NIS should be mainly located in the cytoplasm of cells, the amount of partially glycosylated protein was similar in breast cancer cells and in cells from thyroid carcinomas that did not show intracellular staining (Fig. 3). Some reports have shown, however, that breast tumours can express functional NIS and accumulate iodide (38-40). For example, Berger and collaborators showed that functional NIS was expressed in a benign fibroadenoma and was localized to the plasma membrane (38). Further, Thorpe showed more than 30 years ago that iodide uptake is increased in hormone-responsive mouse mammary tumours (41), suggesting that there is functional NIS in breast tumours. In conclusion, we report the study of 30 breast cancer cases (SBR grades I-III). No anti-NIS antibody staining was observed at the plasma membrane by immunohistochemistry. Very weak intracellular staining was, however, detected in a few samples. This staining corresponds probably to low amounts of partially glycosylated NIS, to the NIS fragment (15 kDa band), or to non-specific binding of 
the antibodies. Nevertheless, our conclusion is that NIS expression is very low in breast cancers and that functional NIS expression is rare. Indeed, a recent study showed that the iodide uptake activity seems to be insufficient in clinical practice for imaging breast carcinomas (42). In any case, enhancing NIS expression in breast cancers (43) remains a very promising approach that could allow the use of induced iodide accumulation for the diagnosis and therapy of malignant breast cells.

Wapnir and collaborators, using tissue microarrays, found anti-NIS antibody staining in a majority of extrathyroidal carcinomas (19). The authors conclude that NIS is predominantly expressed intracellularly in many carcinomas. This conclusion should be re-examined considering our results and a non-specific binding of NIS antibodies.

In conclusion, our data cannot exclude the possibility that defective targeting of NIS contributes to the reduced level of iodide uptake observed in thyroid and breast cancers. However, it is clear that the main cause of this defect is low NIS expression, and not the intracellular localization of overexpressed NIS. These conclusions support the expected correlation between mRNA levels, protein expression, and iodide accumulation capacity in thyroid and breast tumours. Our results indicate that increasing the expression level of NIS should thus remain the major goal to enhance the efficiency of radiotherapy for thyroid cancers and to enable the use of radioiodine in the diagnosis and therapy of breast tumours. Improving NIS targeting to the plasma membrane will not be sufficient.

\section{Declaration of interest}

The authors have no conflict of interest.

\section{Funding}

This work was supported by grants from EDF. A O-M was funded by ECOS-Nord. V N was a recipient of a fellowship funded by the ToxNucE program.

\section{Acknowledgements}

The authors thank Magalie Forchino, Fanny Graslin and Olivier Averseng for excellent technical assistance. The authors wish to thank Dr Patrick Chang for critical reading of the manuscript.

\section{References}

1 Dai G, Levy O \& Carrasco N. Cloning and characterization of the thyroid iodide transporter. Nature $1996 \mathbf{3 7 9} 458-460$.

2 Smanik PA, Liu Q, Furminger TL, Ryu K, Xing S, Mazzaferri EL \& Jhiang SM. Cloning of the human sodium lodide symporter. Biochemical and Biophysical Research Communications 1996226 339-345.
3 Perron B, Rodriguez AM, Leblanc G \& Pourcher T. Cloning of the mouse sodium iodide symporter (mNIS) and its expression in the mammary gland and other tissues.. Journal of Endocrinology 2001 170 185-196.

4 Dohan O, De La Vieja A, Paroder V, Riedel C, Artani M, Reed M, Ginter CS \& Carrasco N. The sodium/iodide symporter (NIS): characterization, regulation, and medical significance. Endocrine Reviews 200324 48-77.

5 Levy O, De La Vieja A, Ginter CS, Riedel C, Dai G \& Carrasco N. N-linked glycosylation of the thyroid $\mathrm{Na}^{+} / \mathrm{I}^{-}$symporter (NIS). Implications for its secondary structure model. Journal of Biological Chemistry 1998273 22657-22663.

6 Smanik PA, Ryu KY, Theil KS, Mazzaferri EL \& Jhiang SM. Expression, exon-intron organization, and chromosome mapping of the human sodium iodide symporter. Endocrinology 1997138 3555-3558.

7 Arturi F, Russo D, Schlumberger M, Du Villard JA, Caillou B, Vigneri P, Wicker R, Chiefari E, Suarez HG \& Filetti S. Iodide symporter gene expression in human thyroid tumors. Journal of Clinical Endocrinology and Metabolism 199883 2493-2496.

8 Ryu KY, Senokozlieff ME, Smanik PA, Wong MG, Siperstein AE, Duh QY, Clark OH, Mazzaferri EL \& Jhiang SM. Development of reverse transcription-competitive polymerase chain reaction method to quantitate the expression levels of human sodium iodide symporter (in process citation). Thyroid 1999 9 405-409.

9 Lazar V, Bidart JM, Caillou B, Mahe C, Lacroix L, Filetti S \& Schlumberger M. Expression of the $\mathrm{Na}^{+} / \mathrm{I}^{-}$symporter gene in human thyroid tumors: a comparison study with other thyroidspecific genes. Journal of Clinical Endocrinology and Metabolism 199984 3228-3234.

10 Park HJ, Kim JY, Park KY, Gong G, Hong SJ \& Ahn IM. Expressions of human sodium iodide symporter mRNA in primary and metastatic papillary thyroid carcinomas. Thyroid $2000 \mathbf{1 0}$ 211-217.

11 Liou MJ, Lin JD, Chan EC, Liu FH, Chao TC \& Weng HF. Detection of mRNA of sodium iodide symporter in benign and malignant human thyroid tissues. Cancer Letters 2000160 75-80.

12 Arturi F, Russo D, Bidart JM, Scarpelli D, Schlumberger M \& Filetti S. Expression pattern of the pendrin and sodium/iodide symporter genes in human thyroid carcinoma cell lines and human thyroid tumors. European Journal of Endocrinology 2001 $145129-135$.

13 Ringel MD, Anderson J, Souza SL, Burch HB, Tambascia M, Shriver CD \& Tuttle RM. Expression of the sodium iodide symporter and thyroglobulin genes are reduced in papillary thyroid cancer. Modern Pathology 200114 289-296.

14 Trouttet-Masson S, Selmi-Ruby S, Bernier-Valentin F, Porra V, Berger-Dutrieux N, Decaussin M, Peix JL, Perrin A, Bournaud C, Orgiazzi J, Borson-Chazot F, Franc B \& Rousset B. Evidence for transcriptional and posttranscriptional alterations of the sodiu$\mathrm{m}$ /iodide symporter expression in hypofunctioning benign and malignant thyroid tumors. American Journal of Pathology 2004 $16525-34$.

15 Jhiang SM, Cho JY, Ryu KY, Deyoung BR, Smanik PA, Mcgaughy VR, Fischer AH \& Mazzaferri EL. An immunohistochemical study of $\mathrm{Na}^{+} / \mathrm{I}^{-}$symporter in human thyroid tissues and salivary gland tissues. Endocrinology $19981394416-4419$.

16 Caillou B, Troalen F, Baudin E, Talbot M, Filetti S, Schlumberger M \& Bidart JM. $\mathrm{Na}^{+} / \mathrm{I}^{-}$symporter distribution in human thyroid tissues: an immunohistochemical study. Journal of Clinical Endocrinology and Metabolism $1998 \mathbf{8 3} 4102-4106$.

17 Castro MR, Bergert ER, Beito TG, Mciver B, Goellner JR \& Morris JC. Development of monoclonal antibodies against the human sodium iodide symporter: immunohistochemical characterization of this protein in thyroid cells. Journal of Clinical Endocrinology and Metabolism 199984 2957-2962.

18 Dohan O, Baloch Z, Banrevi Z, Livolsi V \& Carrasco N. Rapid communication: predominant intracellular overexpression of the $\mathrm{Na}(+) / \mathrm{I}(-)$ symporter (NIS) in a large sampling of thyroid cancer cases. Journal of Clinical Endocrinology and Metabolism 200186 2697-2700. 
19 Wapnir IL, Van De Rijn M, Nowels K, Amenta PS, Walton K, Montgomery K, Greco RS, Dohan O \& Carrasco N. Immunohistochemical profile of the sodium/iodide symporter in thyroid, breast, and other carcinomas using high density tissue microarrays and conventional sections. Journal of Clinical Endocrinology and Metabolism $2003 \mathbf{8 8} 1880-1888$.

20 Tonacchera M, Viacava P, Agretti P, De Marco G, Perri A, Di Cosmo C, De Servi M, Miccoli P, Lippi F, Naccarato AG, Pinchera A, Chiovato L \& Vitti P. Benign nonfunctioning thyroid adenomas are characterized by a defective targeting to cell membrane or a reduced expression of the sodium iodide symporter protein. Journal of Clinical Endocrinology and Metabolism 200287 352-357.

21 Riesco-Eizaguirre G \& Santisteban P. A perspective view of sodium iodide symporter research and its clinical implications. European Journal of Endocrinology 2006155 495-512.

22 Tazebay UH, Wapnir IL, Levy O, Dohan O, Zuckier LS, Hua Zhao Q, Fu Deng H, Amenta PS, Fineberg S, Pestell RG \& Carrasco N. The mammary gland iodide transporter is expressed during lactation and in breast cancer. Nature Medicine 20006 871-878.

23 Cho JY, Leveille R, Kao R, Rousset B, Parlow AF, Burak WE Jr, Mazzaferri EL \& Jhiang SM. Hormonal regulation of radioiodide uptake activity and $\mathrm{Na}^{+} / \mathrm{I}^{-}$symporter expression in mammary glands. Journal of Clinical Endocrinology and Metabolism $2000 \mathbf{8 5}$ 2936-2943.

24 Ronga G, Bruno R, Puxeddu E, Calcinaro F, Montesano T, Travascio L, Colandrea M, Durante C, Maranghi M, Filetti S \& Russo D. Radioiodine uptake in non-lactating mammary glands: evidence for a causative role of hyperprolactinemia. Thyroid 2007 17 363-366.

25 Hedinger C, Williams ED \& Sobin LH. The WHO histological classification of thyroid tumors: a commentary on the second edition. Cancer 198963 908-911.

26 De Stgroth SF \& Scheidegger D. Production of monoclonal antibodies: strategy and tactics. Journal of Immunological Methods $1980351-21$

27 Dayem M, Navarro V, Marsault R, Darcourt J, Lindenthal S \& Pourcher T. From the molecular characterization of iodide transporters to the prevention of radioactive iodide exposure. Biochimie $2006 \mathbf{8 8}$ 1793-1806.

28 Pohlenz J, Duprez L, Weiss RE, Vassart G, Refetoff S \& Costagliola S. Failure of membrane targeting causes the functional defect of two mutant sodium iodide symporters (see comments). Journal of Clinical Endocrinology and Metabolism $2000852366-2369$.

29 Scipioni A, Ferretti E, Soda G, Tosi E, Bruno R, Costante G, Meringolo D, Arturi F, Durante C, Amorosi A, Foschini MP, Nardi F, Russo D \& Filetti S. hNIS protein in thyroid: the iodine supply influences its expression and localization. Thyroid $2007 \mathbf{1 7}$ 613-618.

30 Levy O, Dai G, Riedel C, Ginter CS, Paul EM, Lebowitz AN \& Carrasco N. Characterization of the thyroid $\mathrm{Na}^{+} / \mathrm{I}^{-}$symporter with an anti-COOH terminus antibody. PNAS $1997945568-5573$.

31 Paire A, Bernier-Valentin F, Selmi-Ruby S \& Rousset B. Characterization of the rat thyroid iodide transporter using anti- peptide antibodies. Relationship between its expression and activity. Journal of Biological Chemistry 1997272 18245-18249.
32 Elston CW \& Ellis IO. Pathological prognostic factors in breast cancer. I. The value of histological grade in breast cancer: experience from a large study with long-term follow-up. Histopathology 199119 403-410.

33 Zeng Q, Chen G, Vlantis A, Tse G \& Van Hasselt C. The contributions of oestrogen receptor isoforms to the development of papillary and anaplastic thyroid carcinomas. Journal of Pathology $2008 \mathbf{2 1 4}$ 425-433.

34 Riedel C, Levy O \& Carrasco N. Post-transcriptional regulation of the sodium/iodide symporter (NIS) by thyrotropin. Journal of Biological Chemistry $200127621458-21463$.

35 Zhang Z, Liu YY \& Jhiang SM. Cell surface targeting accounts for the difference in iodide uptake activity between human $\mathrm{Na}^{+} / \mathrm{I}^{-}$ symporter and rat $\mathrm{Na}^{+} / \mathrm{I}^{-}$symporter. Journal of Clinical Endocrinology and Metabolism $2005906131-6140$.

36 Dayem M, Basquin C, Navarro V, Carrier P, Marsault R, Chang P, Huc S, Darrouzet E, Lindenthal S \& Pourcher T. Comparison of expressed human and mouse sodium/iodide symporters reveals differences in transport properties and subcellular localization. Journal of Endocrinology 2008197 95-109.

37 Beyer SJ, Jimenez RE, Shapiro CL, Cho JY \& Jhiang SM. Do cell surface trafficking impairments account for variable cell surface sodium iodide symporter levels in breast cancer? Breast Cancer Research and Treatment, 2008 DOI: 10.1007/S10549-0080059-5.

38 Berger F, Unterholzner S, Diebold J, Knesewitsch P, Hahn K \& Spitzweg C. Mammary radioiodine accumulation due to functional sodium iodide symporter expression in a benign fibroadenoma. Biochemical and Biophysical Research Communications 2006349 $1258-1263$.

39 Moon DH, Lee SJ, Park KY, Park KK, Ahn SH, Pai MS, Chang H, Lee HK \& Ahn IM. Correlation between 99mTc-pertechnetate uptakes and expressions of human sodium iodide symporter gene in breast tumor tissues. Nuclear Medicine and Biology 200128 829-834.

40 Upadhyay G, Singh R, Agarwal G, Mishra SK, Pal L, Pradhan PK, Das BK \& Godbole MM. Functional expression of sodium iodide symporter (NIS) in human breast cancer tissue. Breast Cancer Research and Treatment 200377 157-165.

41 Thorpe SM. Increased uptake of iodide by hormone-responsive compared to hormone- independent mammary tumors in GR mice. International Journal of Cancer 197618 345-350.

42 Buchmann I, Riedmuller K, Hoffner S, Mack U, Aulmann S \& Haberkorn U. Comparison of $(99 \mathrm{~m})$ technetium-pertechnetate and (123)iodide SPECT with FDG-PET in patients suspicious for breast cancer. Cancer Biotherapy \& Radiopharmaceuticals 200722 779-789.

43 Kogai T, Taki K \& Brent GA. Enhancement of sodium/iodide symporter expression in thyroid and breast cancer. EndocrineRelated Cancer 200613 797-826.

Received 6 November 2008

Accepted 13 November 2008 